\title{
Demographic dynamics and natural disasters: learning from Katrina and Rita
}

\author{
William H. Frey • Audrey Singer
}

Published online: 12 January 2010

(C) Springer Science+Business Media, LLC 2010

This special issue of Population and Environment builds on the considerable scholarly work aimed to better understand the causes and consequences that the hurricanes Katrina and Rita have imposed on the Gulf Coast and its residents (see Erikson and Peek (2009), for a review of social science literature related to the hurricanes). This rapid emergence of knowledge is a credit to the many members of the research community in universities, in government and non-profit organizations, who quickly directed their efforts and ingenuity to focus on the why, how, and impacts of some of the most devastating natural disasters in recent US history. Inspired by the suggestion of Population and Environment's Editor-in-Chief, Lori Hunter, this collection grew out of the 2008 Annual Meeting of the Population Association of America, held in New Orleans, Louisiana (USA), which featured early versions of the research published here.

While following the general theme of demographic dynamics and implications of these catastrophes, with special emphasis on migration, the articles reflect a variety of perspectives and draw from different research approaches and data. Much of the work is highly innovative and has important implications for data collection in postdisaster situations.

The issue begins with a paper by Myron Gutmann and Vincenzo Field, that puts the displacement associated with Katrina and Rita in broad historical context. In offering a four-category typology which depicts different ways that environmental forces influence migration, the authors make a provocative argument that environmental calamities, of which Katrina is an example, are relatively rare and have not had a wide impact. They discuss other forms of environmental interactions with migration which may have been stronger and more persistent, though less dramatic.

W. H. Frey · A. Singer $(\bowtie)$

The Brookings Institution, Washington, DC, USA

e-mail: asinger@brookings.edu

W. H. Frey

e-mail: Wfrey@brookings.edu 
The two following papers, by sociologists and demographers, conduct explicit analyses of stratified migration flows resulting from Katrina. The first of these, by Elizabeth Fussell, Narayan Sastry, and Mark Van Landingham, utilizes a pilot survey of displaced residents from New Orleans to investigate the race and class selectivity of return to the city over the 14-month period following the storm. They conclude that although black residents have been slower than whites to return, even after accounting for socioeconomic status, race differences are largely explained by differences in housing damage. Fussell et al. observe that the black population was more likely to live in areas that had greater flooding and thus more extensive housing damage, which had an impact on their return. In the second paper, Jonathan Stringfield identifies Katrina evacuees in data from the Current Population Survey data to examine vulnerable populations that are least prone to return to the Gulf Coast. Among his findings is the conclusion that while blacks show a lesser tendency to return than whites, this effect is mitigated by other vulnerable attributes such as class and household status.

The impacts of displacement are examined in two additional papers. The first, by sociologists Makiko Hori and Mark J. Schafer, utilizes the 2006 Louisiana Health and Population Survey to underscore how a timely survey is necessary to detect negative housing, economic, and health outcomes for evacuees. Taking another approach, economists Paul S. Davies and Jeffrey Hemmeter compare Supplemental Social Security (SSI) records for elderly and disabled individuals with low incomes and assets in areas directly affected by Katrina and Rita with those residing in other areas. They find that those residing in affected areas show more volatile SSI participation and were more likely to leave the program sooner and return at different rates than those in unaffected areas.

Economists Jeffrey Czajkowski and Emily Kennedy model U.S. coastal hurricane fatalities from 1970 to 2007, to assess the costs of non-evacuation during a period of increased population in hurricane-prone coastal areas. In their analyses, they account for the location of the fatality (coastal vs. inland county) as well as the role of evacuation and get results that counter conventional wisdom.

The last paper by demographers Allison Plyer and Ken Hodges, and GIS specialist Joy Bonaguro, gets back to the basics of what data are really needed to monitor the local impacts of hurricanes like Katrina where the population is in a constant state of flux. The authors survey the existing administrative data sources and their relevance for different purposes and put forth useful recommendations.

We wish to thank all the authors for their timely contributions and once again express our gratitude to Lori Hunter for conceiving the idea for this special issue.

\section{References:}

Erikson, K., \& Peek, L. (2009). Hurricane and Katrina Research Bibliography. Social Science Research Council Task Force on Katrina and Rebuilding the Gulf Coast, available at http://katrinaresearch hub.ssrc.org/KatrinaBibliography.pdf. 